\title{
Uso de mídias sociais na interação com a imprensa
}

\section{Use of social mídia and the interaction with the other traditional media}

\section{Jorge Duarte \\ Amanda Dutra Ramos \\ Bianca Smolarek \\ Luciana Farias \\ Sabrina Brito ${ }^{1}$}

\footnotetext{
${ }^{1}$ Jorge Duarte é jornalista, relações-públicas, Doutor em Comunicação e professor de pósgraduação do UniCEUB. Amanda Ramos é jornalista e trabalha como assessora parlamentar na Câmara Federal. Bianca Smolarek é jornalista e trabalha na Agência Brasileira de Desenvolvimento Industrial (ABDI). Luciana Farias é jornalista e trabalha na Engenharia, Construções e Ferrovias S.A (Valec). Sabrina Brito é jornalista e trabalha no Jornal de Brasília. Também autores: Aerton Guimarães, Alexandre Pavoni, Alexandre Scholtz, Aline Sousa Santiago, Ananda Sue, André Sá de Mattos, Bárbara Nogueira, Camila de Magalhães, Clarice Gulyas, Claudivan Santiago, Deise Rosa, Érika Braga, Fernanda Melo, Jassana Chagas, João Paulo Rabelo, José Pedro Morgado, Lidia Mara, Lívia Vasconcelos, Marlúcia Batista Sertão, Renata Pires I. Borges, Sérgio Alberto, Sheila de Oliveira, Sheylla da Silva, Thays Ferrari Puzzi, Tiago Prates, Vanessa Martins, Walisson de Oliveira, todos são alunos de pós-graduação do curso de Gestão da Comunicação do UniCEUB.
}

\section{Resumo}

Este trabalho é um Relato de Pesquisa de campo, realizada a partir da verificação do uso de mídias sociais em 64 ambientes web de diferentes organizações e de entrevista com 7 profissionais de comunicação que atuam no relacionamento com a imprensa, e com 14 jornalistas. O objetivo foi avaliar o uso e potencial das redes sociais para qualificar e ampliar o relacionamento entre organizações e a imprensa. Ao final, constata-se que o uso ainda é restrito à distribuição de conteúdo veiculado em outros ambientes web e que o potencial de interação de dupla via com a imprensa é desprezado.

Palavras-chave: Mídias sociais. Jornalismo. Assessoria de Imprensa. Serviço Público.

\begin{abstract}
This work is a Report of Field Research carried out through the observation of the use of social media in 64 web environments of different organizations and through an interview done with 7 communication professionals working and dealing in the traditional media, as well as with 14 journalists. The objective was to evaluate the use and the potential of social networks in order to qualify and to improve the relationship between organizations and the traditional media. At the conclusion, it was verified that the use is still limited to content distribution released in other web environments and that the two-way potential of interaction with the traditional media is disregarded.
\end{abstract}

Kewwords: Social media, Journalism, press agentry, public service. 


\section{Introdução}

Durante sua evolução, o jornalismo passou por diversas transformações técnicas. Desde o final do século $\mathrm{XX}$, enfrenta a adaptação às inovações tecnológicas resultantes do surgimento da internet como nova plataforma de informação. Um dos resultados é a ampliação das possibilidades de produção noticiosa, com novas e notáveis ferramentas capazes tanto de ampliar o trabalho de geração e distribuição de conteúdo, como de permitir a qualquer pessoa também assumir este papel. $\mathrm{O}$ ambiente online possui enorme capacidade de garantir o compartilhamento de informações e a interlocução entre os envolvidos. O conteúdo disponibilizado é passível de críticas, sugestões e o feedback pode ser dado em tempo real.

As mídias sociais (ou Web 2.0) foram uma das mais recentes novidades, e ambientes (como: Twitter, Facebook, Formspring, Foursquare, LinkedIn, Orkut, Blogs) e redes de compartilhamento (como: Youtube, Picasa, Fli$c k r$, SlideShares ou SoundCloud) se tornam rapidamente populares ao potencializar a capacidade de interação em espaços especializados de amplo e fácil acesso. A imprensa, antes restrita a sites e portais, ampliou o uso dessas novas alternativas para uma distribuição rápida, fácil e até bastante informal do conteúdo. Ao mesmo tempo, fontes de informação primárias, como: autoridades, técnicos, dirigentes, lideranças, artistas e profissionais liberais, ganham capacidade de distribuir conteúdo, apoiados ou não por estruturas especializadas, como agências de comunicação, de relações públicas ou assessorias de imprensa. E ter um canal direto com a imprensa, com acessos a vídeos, press releases, e-mails e telefones, e outros suportes, agiliza a divulgação das informações de interesse, bem como permite o feedback, praticamente instantâneo, dos jornalistas e público em geral.

\section{Procedimentos metodológicos}

O presente trabalho teve como objetivo investigar como instituições do poder público e de empresas privadas utilizam as mídias sociais para interagir com a imprensa. Para isso, foram examinadas 64 contas cadastradas em mídias sociais e verificado o uso de ferramentas para interação com a imprensa por órgãos públicos dos poderes Judiciário, Executivo e Legislativo, de níveis municipal, estadual e federal. Ao mesmo tempo, realizamos entrevistas com jornalistas e com assessores de comuni- cação. Buscou-se, essencialmente, analisar o uso de mídias sociais pelas assessorias de imprensa e compreender a visão de repórteres que buscam informações nesses ambientes. Os resultados indicam as principais características/peculiaridades encontradas no uso de mídias sociais pelos órgãos analisados, além de uma avaliação geral do grupo de pesquisa.

A pesquisa e a análise sobre o uso das mídias sociais como ferramenta de relações com a imprensa foram efetuadas entre 03 e 11 de fevereiro de 2012, como atividade da disciplina Assessoria de Imprensa e Media Training, do curso de Gestão da Comunicação nas Organizações, oferecido pelo Centro Universitário de Brasília, UniCEUB. Os pós-graduandos da Turma A-2011 se dividiram em sete grupos para investigar o tema. Cada um analisou de oito a doze perfis nas redes sociais e o uso desta ferramenta na divulgação de informações para a imprensa e no relacionamento com jornalistas. Cada grupo entrevistou um (01) profissional de assessoria de imprensa e dois (02) jornalistas de diferentes órgãos para conhecer a opinião quanto à utilização das mídias sociais na interação entre organizações e repórteres. Os resultados foram sistematizados por quatro alunas e o professor da disciplina. As informações originais foram obtidas mediante entrevista por email, telefone e pessoalmente. As mídias sociais verificadas na pesquisa junto às organizações foram, particularmente, Facebook, Orkut, Blogs, Twitter, SoundCloud, YouTube, Formspring, Foursquare, LinkedIn, Picasa, Flickr, SlideShares. Os pesquisadores fizeram testes para verificar sistemas de atendimento e de informação.

As organizações privadas examinadas foram: Coca-Cola, McDonald's, Natura, Tecnisa, Vivo, Citroën, Chevrolet, Fiat, Ford, Peugeot, Toyota, Volkswagen, Centro Universitário de Brasília - UniCEUB, Instituto de Educação Superior de Brasília - IESB e Universidade Católica de Brasília. Além das entidades associativas: Confederação Brasileira de Futebol - CBF, Confederação Nacional da Indústria - CNI. As instituições públicas foram: Câmara dos Deputados, Câmara de Vereadores de Passo Fundo (RS), Câmara Municipal de Formosa (GO); Ministérios da Aeronáutica, Agricultura, Cidades, Cultura, Desenvolvimento Social e Combate à Fome, Educação, Exército, Justiça, Marinha, Pecuária e Abastecimento, Esporte, Planejamento, Trabalho e Emprego, Previdência Social, Saúde e Turismo; governos da Bahia, Distrito 
Federal, Pará, Santa Catarina e São Paulo; secretarias da Cultura e do Turismo do Distrito Federal; além disso, examinaram-se, também, Advocacia Geral da União (AGU), Administração Regional de Sobradinho (DF), Fundação do Patrimônio Histórico e Artístico de Pernambuco, Palácio do Planalto, Petrobras, Prefeitura Lauro de Freitas (BA), SOS Imprensa (UnB), Superintendência de Estudos Econômicos e Sociais da Bahia, Supremo Tribunal Federal - STF, Superior Tribunal de Justiça - STJ, Tribunal de Justiça do Distrito Federal e Território, Tribunal Superior Eleitoral e Universidade de Brasília - UNB. Os partidos políticos que tiveram seus sites examinados foram: Democratas (DEM), Partido do Movimento Democrático Brasileiro (PMDB), Partido Social Cristão (PSC), Partido da Social Democracia Brasileira (PSDB), Partido Socialista Brasileiro (PSB), Partido dos Trabalhadores (PT), Partido Trabalhista Brasileiro (PTB) e Partido Verde (PV).

\section{Resultados e discussão}

Em nossa pesquisa, e apesar da massiva presença das organizações na rede, não ficou caracterizado o uso frequente de ferramentas de interação pelas organizações pesquisadas para relacionamento com a imprensa e, mesmo, com o público em geral. Na maioria das vezes, a comunicação efetiva com os jornalistas se dá por meio de meios tradicionais - os sites oficiais. O caso mais explícito parece ser o dos partidos políticos. Apenas dois deles, o Partido dos Trabalhadores e o Partido da Social Democracia, mantêm atuação constante nas mídias sociais (@rede45, com 34.918 seguidores e @ptbrasil, com 36.168 seguidores no momento da pesquisa), atuando os outros muito mais como replicadores de conteúdo gerados no próprio ambiente ou em terceiros. Apesar da anunciada profissionalização e de a comunicação promovida pelos grandes partidos nas redes sociais ser bastante completa (com conteúdos em áudio, vídeo e texto, ações e campanhas com links para diversas matérias e órgãos relacionados), a pesquisa constatou, porém, que se trata de uma presença digital extremamente institucional, impessoal e oficial.

Os perfis estaduais dos partidos apresentam, mesmo que raramente, comunicação direta com os seguidores. No entanto, o conteúdo divulgado não é diferenciado, nem amplo, e não parece haver uma estratégia de integração com os perfis nacionais oficiais. As páginas voltadas para a militância jovem são as que atuaram de forma mais participativa e informal (destaque para a @juventudedoPT), contudo, de forma geral, não foram observadas características interativas nas redes sociais dos partidos com jornalistas.

As assessorias de imprensa dos órgãos públicos analisados também utilizam as mídias sociais de forma apenas tímida. A demora no atendimento e as respostas automáticas podem causar a desistência do seu uso. A interatividade e a instantaneidade das informações, principais vantagens da utilização dessas ferramentas, são praticamente desprezadas.

Um problema observado, e presente em maior escala na área privada, é o da falta de adequação na linguagem utilizada nas diferentes mídias. Se o objetivo é potencializar, por meio desses canais, a divulgação de informações institucionais e atividades de relevância para o público, esse processo fica prejudicado com a pouca produção específica e diferenciada para mídias sociais, predominando a replicação de títulos de matérias já disponibilizadas no site ou via mailling e mala direta. É comum a existência de perfis desatualizados para os padrões desses ambientes web. Ao mesmo tempo, há casos interessantes como o da empresa Vivo, que, por meio de seu perfil @ vivoimprensa no Twitter, vai além do abastecimento dos veículos de comunicação com informações institucionais. Quando possível, os assessores responsáveis pelo perfil agem de maneira intimista com seus seguidores, tirando dúvidas e até mesmo trocando mensagens que não tratam da relação profissional (um desejo de melhoras para a jornalista que relatou estar doente, por exemplo).

Mesmo que as outras contas institucionais nas redes não apresentem de maneira tão premente conteúdo exclusivo aos repórteres, é notório que facilita, ao profissional de comunicação, receber atualizações no próprio feed de notícias. Assim, não precisam recorrer aos portais para ter acesso à informação. Trata-se de facilidade de tempo e de acesso, o que não quer dizer que não encontrem dificuldades na interação e na busca de dados e fontes mais específicas.

Dentre todos os perfis analisados, os que mais se sobressaíram, quanto à possibilidade de relacionamento e relevância para os jornalistas, foram os Twitters da AGU, institucional da Petrobras e do STF, Facebook do GDF e da CBF, Blog da Petrobrás e o YouTube do STF. Na conta da CNI, no Twitter, a relação é quase que exclusiva aos 
jornalistas, o que se denota pelo perfil @jornalismocni. Além de notícias sobre pesquisas e dados da indústria, no perfil, constam os números de telefone da Assessoria de Imprensa para facilitar o contato. Já o perfil da Toyota, no Twitter, é exclusivo à imprensa. Nele, todos os links dos tweets só podem ser acessados mediante cadastro preliminar, no qual o interessado deve mencionar para qual tipo de veículo ele trabalha. De fato, as notícias postadas na página da montadora apresentam caráter basicamente informativo, com links que levam a notícias sobre eventos automotivos, parcerias firmadas, resultados de projetos de sustentabilidade, informes de produção, entre outros. O que se percebe é o foco em mostrar a empresa nas dimensões econômica, social e ambiental, na tentativa de prestar contas à comunidade por meio da imprensa.

A importância dos órgãos públicos, tais como a AGU e o STF, e as decisões por eles tomadas ou conquistadas garantem relevância para qualquer público. No $F a$ cebook, a produção de conteúdo foi destaque no caso da CBF e a interação, no caso do GDF. O YouTube do STF se destaca por ser também um bom banco de imagens, que podem ser utilizadas como material jornalístico. Entre os que foram mais mal avaliados estão o Facebook da AGU, pela automação da publicação de notícias sem a formatação ideal para o meio; os perfis do McDonald's, por não ter boa produção de conteúdo. Há outros casos que mostram ainda ótima atuação nas mídias sociais, porém voltadas para o consumidor, o que não é objeto desta análise.

Notam-se, portanto, a falta de relevância e o conflito de perfis institucionais voltados diretamente para jornalistas. Nos casos analisados, todos os perfis voltados para relacionamento com imprensa são quase que réplicas dos perfis principais, perdendo em relevância e em relacionamento, o que é comprovado pela menor quantidade de perfis relevantes que o seguem. Assim, podemos destacar que, nesta análise, o conteúdo nas mídias sociais é direcionado para os stakeholders em geral e não só para jornalistas especificamente.

As assessorias, em geral, não criam conteúdos adaptados às novas mídias, costumando reproduzir nas mídias sociais o que já enviaram por e-mail. Há vários canais, mas não há aproveitamento pleno. Como a web 2.0 é um fenômeno novo, nota-se que muitas organizações ainda se sentem inseguras nas redes e que as mídias sociais não são utilizadas como ferramentas efetivas de assessoria de imprensa.
A percepção de que as mídias sociais não são utilizadas como ferramentas efetivas de assessoria de imprensa é ratificada pelos repórteres entrevistados nesta pesquisa - entre eles, há quem sequer considere as redes sociais como possíveis ferramentas de trabalho. A maioria relatou que consulta frequentemente as mídias sociais para apuração de dados e informações, mas que raramente as usa como acesso a propostas de pautas, assessores de comunicação ou fontes. Nas poucas vezes em que isso ocorre, geralmente é por meio de mensagem privativa (equivalente ao e-mail) e não pela interação "aberta", que caracteriza as redes sociais.

Os jornalistas consideram ser mais efetivo, nas redes, se relacionar com colegas e outros veículos de comunicação para acompanhar as pautas, debates e agendas do dia, como uma espécie de "termômetro". Além disso, muitas vezes, as redes disseminam informações que ainda não foram noticiadas pela imprensa - por sua natureza editorial ou política - mas que podem se tornar pautas interessantes. Foram citados, como exemplos, desde vídeos de grande sucesso no Youtube até as manifestações políticas no Oriente Médio. A disseminação, nas redes, de informações sobre conflitos políticos, burlando o controle local, também é tomada como exemplo desse tipo de uso dessas mídias pela imprensa.

Para os jornalistas, a utilização das redes sociais na interação com as assessorias de imprensa e fontes pode gerar a exposição indevida ou prematura das pautas que estão em andamento, assim como das próprias fontes. Outro complicador observado é que, se a assessoria pretende comunicar o fato a um veículo e ganhar um bom espaço, a informação tem de ser divulgada de forma mais restrita. Caso o dado entre nas redes sociais, dependendo da sua importância, a assessoria vira uma espécie de concorrente do veículo de comunicação.

Entre as principais vantagens no uso das redes sociais como fonte de insumo jornalístico, foram apontados pelos repórteres: a rapidez no acesso à informação; maior proximidade com as fontes; e o barateamento do acesso às fontes e assessores. Por sua vez, foram citadas como desvantagens: a grande quantidade de informações irrelevantes; a dificuldade de separação entre o uso pessoal e profissional da rede (tanto para fontes e assessores quanto para jornalistas); a eventual falta de ética; e a ocorrência constante de erros de português (que podem tirar a credibilidade do autor). 
Nas entrevistas com repórteres, também foram identificadas críticas diretas aos procedimentos rotineiros das assessorias de comunicação. A primeira é de que, ao invés de utilizar as redes sociais para interagir com a imprensa, muitas aproveitam as redes como meros espaços para promoção dos seus assessorados. Outro fato observado é que, na maior parte do tempo, as assessorias reproduzem nessas mídias conteúdos já publicados ou distribuídos em outros meios e o fazem com atraso, o que vai de encontro ao dinamismo que os jornalistas e os demais usuários das redes buscam. Os repórteres destacaram, ainda, que uma informação ou declaração colocada nas redes sociais nem sempre "esgota" o assunto e que, portanto, isso deve ser uma das etapas da divulgação da informação, não a única. Segundo eles, o contato e a apuração "in loco", com entrevistas por telefone ou pessoalmente, serão sempre necessários.

A maioria dos assessores de imprensa entrevistados para esta pesquisa afirma que as organizações têm utilizado as redes sociais para informar a sociedade em geral - o que inclui a imprensa, mas sem tratamento especializado para ela. Nesses espaços, as companhias pouco segmentam o público. Pelo contrário, buscam alcançar, ao mesmo tempo, diversos grupos, de muitas regiões diferentes. Essa seria, na visão de vários assessores, uma das grandes vantagens das redes.

Sinal de que esses espaços são encarados pelos assessores de comunicação mais como forma de contato com o público em geral, e menos como uma ferramenta de assessoria de imprensa, é a recorrência com que os assessores entrevistados citaram a importância do contato direto com o cidadão nas redes. Ou seja, o papel dos jornalistas como mediadores de informação acaba esvaziado nesses meios sociais, nos quais as organizações não necessitam "terceirizar" a comunicação com a sociedade via imprensa.

A maioria dos assessores entrevistados observa que a imprensa está, sim, muito próxima das organizações nas redes sociais e que isso pode gerar pautas para os veículos de comunicação. Mas, quando isso ocorre, a ação de assessoria de imprensa é vista como uma próxima etapa, que acontece quase que integralmente em outros meios, como telefone, e-mail e contato pessoal.

Os profissionais de comunicação entrevistados junto às organizações pesquisadas dizem utilizar as redes sociais como ferramentas de monitoramento da imagem da organização, mas não a utilizam como estratégia de relacionamento com a imprensa, o que encontra amparo na avaliação feita diretamente nos sites. O monitoramento, entretanto, parece subsidiar diversos outros tipos de estratégias, como indica a declaração de um dos entrevistados de que isso é considerado, entre outras coisas, como ferramenta de apoio às decisões gerenciais.

Apesar das limitações identificadas na pesquisa, a ação das assessorias de imprensa nas redes não pode ser caracterizada como nula. Embora praticamente nula no estabelecimento de diálogos entre organizações e imprensa, as informações transmitidas pelas redes sociais chegam a muitos jornalistas. O maior sucesso parece ser das organizações que apostam na agilidade. São exemplos disso entidades ligadas ao Poder Judiciário, capazes de informar em tempo real detalhes sobre julgamentos que estão em andamento, com grande audiência e interesse de jornalistas.

\section{Conclusões}

A área de relacionamento com a imprensa de uma organização tem a função de interagir com os jornalistas, com o objetivo de tornar a companhia e seus produtos/ serviços reconhecidos no mercado, prestar informações e orientações de interesse público, atender a demandas e qualificar a informação que irá circular na sociedade. A área atua com informações de características noticiosas, de forma a atrair o interesse jornalístico para o tema, conquistando assim espaço editorial em mídias eletrônicas e impressas. Logo, as assessorias de impressa nas redes sociais podem, com informações imediatas, relevantes e multimídias, tornar esse relacionamento mais produtivo.

Apesar do desenvolvimento e potencial das mídias sociais, a maior parte das organizações pesquisadas não parece reconhecer os jornalistas como público-alvo relevante a ser alcançado por estas ferramentas. Mais que isso, os testes realizados em sites mostram que as diferentes áreas que administram estes ambientes, em grande maioria, não respondem no prazo e nem retornam com eficiência pelos diferentes canais oferecidos. Ter vários perfis não é sinônimo de participação e interação. Parece haver grande preocupação com a oferta de press releases e replicações de conteúdo dos sites institucionais e pouca atenção para interação e postagem de material exclusivo e segmentado. 
Assim, no universo pesquisado, as redes sociais, por diferentes motivos, são pouco utilizadas pelas áreas de comunicação para interação específica com a imprensa e, quando adotadas, não parecem merecer relevância. Novos trabalhos nesta área podem permitir aprofundar as objeções, limitações ou restrições sobre este uso. Estudos de caso podem aumentar a compreensão e alternativas sobre seu uso potencial para qualificar a interação entre organizações e imprensa.

\section{Referências}

CAMPOMAR, Marcos Cortez. Do uso de "estudo de caso" em pesquisas para dissertações e teses em administração. Revista de Administração, São Paulo, v. 26, n.2, p. 95-97, jul./set. 1991.

COMM, Joel. O Poder do Twitter: estratégia para dominar seu mercado e atingir seus objetivos com um tweet por vez. São Paulo: Gente, 2009.

DUARTE, Jorge; CARVALHO, Nino. Sala de Imprensa Online. In: DUARTE, Jorge (Org.). Assessoria de Imprensa e Relacionamento com a Mídia. 4. ed. São Paulo: Atlas, 2011.

GIL, Antonio Carlos. Métodos e técnicas de pesquisa social. São Paulo: Atlas, 1987.

MARTINS, Joel; BICUDO, Maria Aparecida V. A pesquisa qualitativa em psicologia: fundamentos e recursos básicos. São Paulo: Moraes, 1989.

JENKINS, Henry. Cultura da Convergência. São Paulo: Aleph, 2008. 